\title{
Accrual Reporting Method Code
}

National Cancer Institute

\section{Source}

National Cancer Institute. Accrual Reporting Method Code. NCI Thesaurus. Code C93493.

A coded value specifying the technique that is used for reporting subject accrual data to the study sponsor. 